\title{
End-of-Life Hospital Costs in Cancer Patients: Do Advance Directives or Routes of Hospital Admission Make a Difference?
}

\author{
Tow S. Tan Aminah Jatoi \\ Department of Oncology, Mayo Clinic, Rochester, Minn., USA
}

\author{
Key Words \\ Cancer $\cdot$ End of life $\cdot$ Cost $\cdot$ Hospitalization
}

\begin{abstract}
Objective: End-of-life cancer care is costly. The current study explored whether advance directives or route of hospital admission reduced cancer patients' terminal hospitalization costs. Methods: This single-institution study focused on solid tumor patients who died on an inpatient oncology service in 2008 and 2009. Patients' total costs were compared based on advance directives and route of hospitalization. Results: Among 120 patients, all except 4 had an incurable malignancy. Forty-six (38\%) had an advance directive. Sixteen (13\%) were admitted after an oncology clinic visit and 6 (5\%) from hospice; others were admitted via other routes, most commonly from the emergency department. The median total cost for hospitalization (range) per patient was USD 12,962 $(1,244-138,877)$. Patients with advance directives had no statistically significant difference in cost $(p=0.30)$, even after adjusting for age and time in the hospital. Those admitted after an oncology clinic or from hospice also had no difference in cost compared to those admitted via another route. Use of cardiopulmonary resuscitation, intensive care unit monitoring and intubation were similar between all compared groups. Conclusion: Advance directives and route of admission do not appear to impact the cost of terminal hospitalization for cancer patients.
\end{abstract}

Copyright ๑ 2011 S. Karger AG, Basel
In the United States, over USD 80 billion per year are spent on end-of-life care, and slightly under half goes to end-of-life interventions for cancer patients. The costs of treating patients with cancer of the breast, colorectal area and lung in the very last year of life are USD 3 billion, 3.6 billion and 4.2 billion, respectively [1]. Admittedly, some of these costs go towards covering expensive antineoplastic agents but also, at times, they go towards implementing so-called 'heroic' interventions, such as cardiopulmonary resuscitation, intensive care unit monitoring and intubation - many of which are undertaken in the very last days of life.

Such end-of-life costs have been described as a 'burden to people diagnosed with cancer, their families, and society as a whole' [1]. What can be done to reduce them? A few studies have examined whether advance directives have a salutary effect on reducing such high costs $[2,3]$. Advance directives are patient-completed documents that can include a living will, healthcare proxy and a durable power of attorney, the former of which can designate the types of medical treatment a patient desires, particularly at the end of life [4]. These earlier studies have hypothesized that patients' pondering end-of-life issues and writing down their wishes in an advance directive result in reduced healthcare costs. However, this approach has not always translated into patients' requesting less aggressive - and therefore less expensive care - and, in fact, these studies have yielded mixed conclusions [2, 3]. Perhaps advance directives are not as important as

\section{KARGER}

Fax +4161306 1234 E-Mail karger@karger.ch www.karger.com
() 2011 S. Karger AG, Basel

Accessible online at: www.karger.com/ocl
Aminah Jatoi, MD

Department of Oncology, Mayo Clinic

200 First Street SW

Rochester, MN 55905 (USA)

E-Mail jatoi.aminah@mayo.edu 
face-to-face conversations between patients and a healthcare provider immediately prior to a major decline in status, such as those which would occur immediately before a terminal, end-of-life hospitalization [5]. To our knowledge, this latter approach has not been previously explored from a cost standpoint. However, escalating healthcare costs coupled with a relative paucity of studies that clearly define the cost-related effects of advance directives and route of hospitalization suggest a need to pursue further studies in this area.

Hence, the current study was undertaken. Importantly, few such studies have focused on cancer patients. Yet, the emotionally charged nature of a cancer diagnosis coupled with patients' heightened awareness of their own mortality following such a diagnosis - suggest that if either of the two foregoing approaches were to reduce endof-life costs, they would do so in this group of patients. Thus, this exploratory study was undertaken to assess terminal hospitalization costs among cancer patients within the context of advance directives and route of admission.

\section{Methods}

\section{Overview}

The Mayo Clinic Institutional Review Board deemed this study exempt. Utilizing a retrospective study design, we focused exclusively on solid tumor oncology patients' last hospitalization during the years 2008 and 2009. These dates were chosen because they are recent, included a sizable number of patients, and, by design, did not require an inflation-related adjustment over time because of this short, 2-year interval.

\section{Ascertainment of Records and Clinical Information}

All patients who had died on an inpatient oncology service at the Mayo Clinic during the above dates were included in this study. One investigator (T.S.T.) reviewed each medical record for the following information: patient age at death, gender, cancer diagnosis, admission diagnosis, whether the cancer was curable or not at the time of admission, and whether or not an advance directive had been completed prior to hospitalization. Each record was also searched to find route of entry into the hospital, as per the following categories: through the emergency department, by means of a phone call without the oncologist's having seen the patient immediately prior, via the oncology clinic, by means of an intramural hospital transfer, through hospice or transferred from an outside hospital.

Other information gleaned from the medical record included whether a patient underwent cardiopulmonary resuscitation after hospitalization, was admitted to an intensive care unit, or was intubated. Information on whether or not a palliative care specialist was consulted was also obtained.

Subsequently, all medical records were further scrutinized for the content of information in the advance directive and the nature of the face-to-face conversation between the oncologist and the patient prior to admission. Documentation of such conversations between a palliative care provider and the patient was not accessible to the study team for patients enrolled in hospice.

\section{Definition of Total Cost}

This study used total cost as the primary endpoint. Total cost was defined as the entire sum of money required to provide a medical service after adjustment for the average cost of such services for a given year. This measure was thought to be the most appropriate financial outcome measure, and it was provided directly by hospital accounting services.

Analyses

Comparative statistics were performed with a Wilcoxon rank sum test or t test, as appropriate. Data that did not conform to a normal distribution were log-transformed for multivariate analyses to assess the relationship between the existence of an advance directive and cost with adjustments for time in the hospital and patient age at death. The relationship between total cost and routes of entry into the hospital was also assessed. Entry via the oncologist's office and hospice were collapsed into one category a priori, as, based on an established relationship between the patient and healthcare provider, both were thought to be associated with a higher likelihood of an in-depth, meaningful conversation between the patient and healthcare provider. Total costs based on routes of entry into the hospital were compared after adjustment for days in the hospital and patient age at death. A p value of $<0.05$ was considered statistically significant.

\section{Results}

\section{Demographics}

A total of 120 solid tumor oncology patients died during this 2-year period, and this group constitutes the focus of this report. These patients consisted of 62 men and 58 women. The median age (with range in parentheses) at death was 61 years $(24,85)$. All except $4(97 \%)$ had an incurable malignancy. Other demographics are listed in table 1.

\section{Hospitalization and Advance Directives}

The median time (range) in the hospital per patient prior to death was 4 days $(0,35)$. Forty-six patients (38\%) had had an advance directive on admission. In terms of route of hospital admission, 56 (47\%) were admitted through the emergency department, 25 (21\%) by means of a phone call without the oncologist having seen the patient immediately prior, 16 (13\%) immediately after an oncology clinic visit, 8 (7\%) by means of an intramural hospital transfer, 6 (5\%) directly from hospice and $9(7 \%)$ were transferred from an outside hospital. 


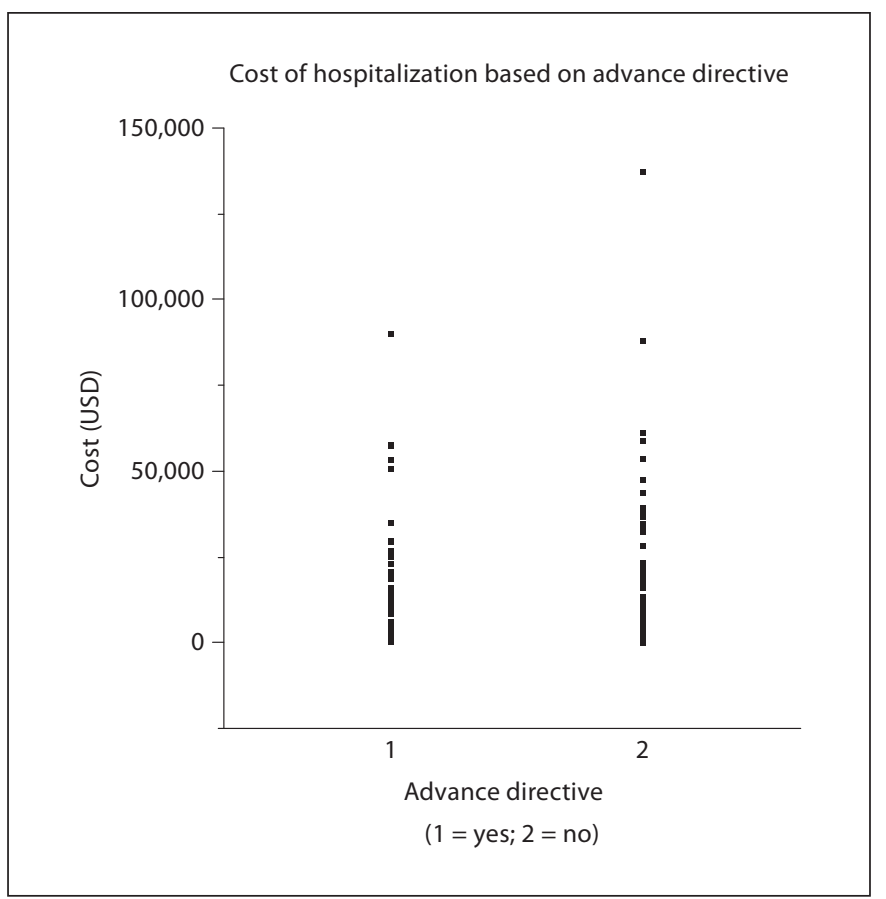

Fig. 1. Costs were not statistically different between patients based on whether or not they had an advance directive, even after adjustment for other factors.

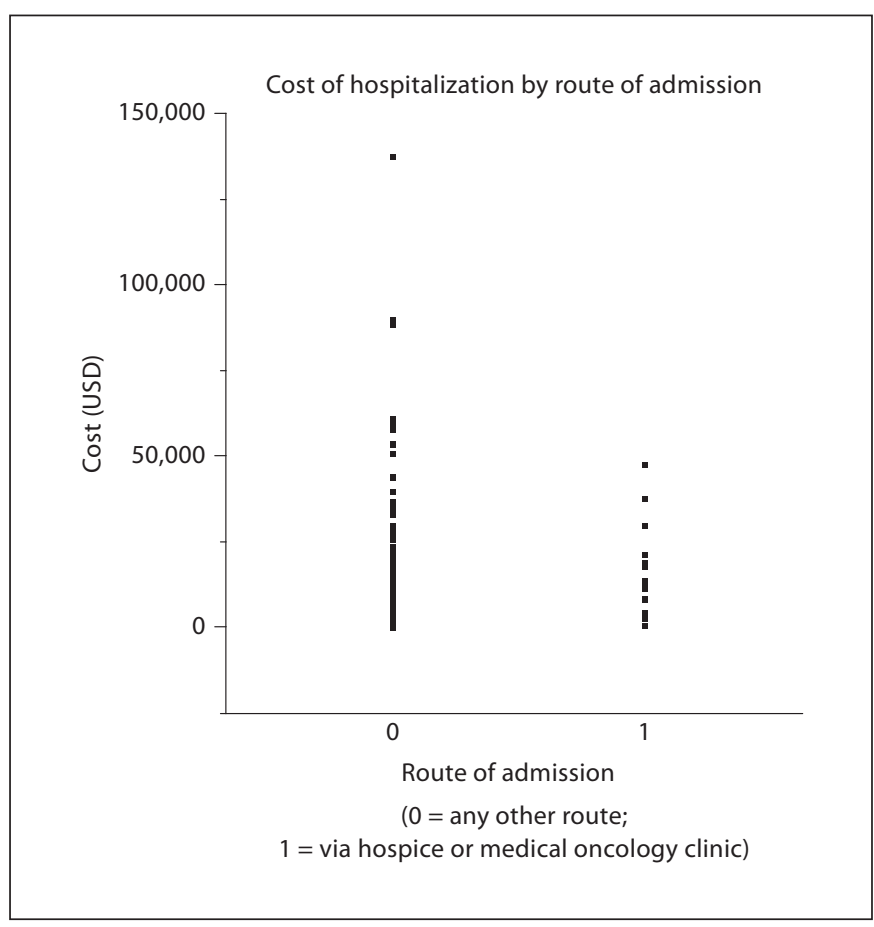

Fig. 2. Costs were not statistically different between patients based on route of hospitalization, even after adjustment for other factors.
Table 1. Patient demographics $(n=120)$

\begin{tabular}{|c|c|c|}
\hline & $\begin{array}{l}\text { Patients } \\
\text { with } \\
\text { advance } \\
\text { directives } \\
(\mathrm{n}=46)\end{array}$ & $\begin{array}{l}\text { Patients } \\
\text { without } \\
\text { advance } \\
\text { directives } \\
(\mathrm{n}=74)\end{array}$ \\
\hline Median age at death, years ${ }^{1}$ (range) & $62(32-85)$ & $61(24-85)$ \\
\hline \multicolumn{3}{|l|}{ Gender } \\
\hline Male & $25(54)$ & $37(50)$ \\
\hline Female & $21(46)$ & $37(50)$ \\
\hline \multicolumn{3}{|l|}{ Cancer curable? } \\
\hline Yes & $3(7)$ & $1(1)$ \\
\hline No & $43(93)$ & $73(99)$ \\
\hline \multicolumn{3}{|l|}{ Cancer diagnosis } \\
\hline Gastrointestinal & $16(35)$ & $25(34)$ \\
\hline Lung & $10(22)$ & $24(32)$ \\
\hline Breast & $3(7)$ & $6(8)$ \\
\hline Genitourinary & $5(11)$ & $3(4)$ \\
\hline Other & $12(26)$ & $16(22)$ \\
\hline \multicolumn{3}{|l|}{ Admission main symptom/diagnosis } \\
\hline Dyspnea & $9(20)$ & $22(30)$ \\
\hline Pain & $11(24)$ & $12(16)$ \\
\hline Infection & $3(7)$ & $8(11)$ \\
\hline Weakness & $6(13)$ & $10(14)$ \\
\hline Pulmonary embolus/thrombophlebitis & $3(7)$ & $3(4)$ \\
\hline Nausea/vomiting & $3(7)$ & $8(11)$ \\
\hline Other & $11(24)$ & $11(15)$ \\
\hline
\end{tabular}

${ }^{1}$ Figures in parentheses are percentages, unless indicated otherwise. Percentages may not sum to $100 \%$ because of rounding.

\section{Total Costs}

The median total cost for hospitalization per patient was USD 12,962 (range: 1,244-138,877). The interquartile range of $25-75 \%$ was USD 6,760-23,375. Patients who had had an advance directive had a median total terminal hospitalization cost per patient of USD 12,840, and those without had one of USD 13,084 ( $\mathrm{p}=0.30$ ) (fig. 1). Patients who had been admitted to the hospital after an oncology clinic visit or hospice visit had a median total terminal hospitalization cost per patient of USD 25,320, and those who had entered the hospital via another pathway had a cost of USD 24,335 ( $\mathrm{p}=0.43$ ) (fig. 2).

After adjusting for patient age at death and days in the hospital, the existence of an advance directive was not associated with a statistically significant difference in total hospital cost $(p=0.24)$. The same was found for route of hospitalization $(\mathrm{p}=0.51)$.

Consistent with the above findings, 24 of 120 patients (20\%) underwent cardiopulmonary resuscitation during 
their final hospital admission, $61(51 \%)$ were admitted to the intensive care unit and $22(18 \%)$ were intubated. Although these interventions were associated with higher costs, no statistically significant differences were observed with respect to the use of these interventions based on the existence of an advance directive or route of hospitalization. Of note, only 16 patients (13\%) had had a palliative care consult, and this consultation generally occurred at the very end of hospitalization when cost could not have been notably impacted.

\section{Specifics on Advance Directives and Encounters with Oncologists}

Among the 46 patients who had an advance directive, 32 mentioned end-of-life, heroic interventions and stated that they should not be employed. However, these advance directives clearly stated that such end-of-life, heroic interventions were contingent upon the patient's reaching a point after which there would be no prospect of meaningful recovery; the latter was never clearly defined or explained in the document.

All except one advance directive appeared to be derived from a template. These templates often asked openended questions with little preceding explanatory or educational materials that might have provided guidance for the patients. For example, one included the following statement: 'If I had a reasonable chance of recovery, and were temporarily unable to decide or speak for myself, I would want [fill in the blank].' Another asked patients to place their initials next to one of the following choices: 'no life sustaining treatment, treatment for restoration, treatment unless permanently unconscious, or maximum treatment.' Each category also provided further explanation beyond these choices, but there was no guidance or specific discussion of circumstances that outlined why a patient might choose one over another.

In terms of outpatient encounters with oncologists on the day of hospitalization, only 7 of 16 such visits alluded to an end-of-life conversation in the last outpatient clinic note, despite the fact that all these patients had an incurable malignancy. Three of these patients and their healthcare providers discussed future chemotherapy on the day of hospitalization.

\section{Discussion}

This single-institution study set out to evaluate cost of hospitalization among cancer patients who died on an inpatient oncology service. The intention was to explore whether the existence of advance directives or route of hospitalization, the latter of which included a face-to-face discussion with an oncology or presumably palliative care provider, was associated with lower end-of-life hospitalization costs. Surprisingly, neither an advance directive nor a same day discussion with an oncology or palliative care healthcare provider reduced costs. Indeed, the rates of cardiopulmonary resuscitation, intensive care unit admission and intubation were not statistically different between the groups described above.

What explains this lack of associations? Ever since Congress passed the Patient Self-Determination Act, which encouraged the use of advance directives, these documents appear to have received increasing attention and promotion [6]. And, indeed 46 (38\%) patients in this study did have an advance directive, presumably as a result of this legislation. However, a substantial percentage of these documents (15 of 46) lacked specifics about endof-life care. Those that did discuss end-of-life care typically carried the contingency that patients' stated wishes should only be utilized if it was absolutely certain that death was immediately inevitable and specifics relevant to this latter point were never spelled out. Moreover, in examining oncologists' documented discussions on the day of hospital admission, it appears that only a minority (7 of 16) discussed end-of-life issues. In short, despite the fact that the vast majority of these patients had a lethal cancer diagnosis and despite the fact that many were presenting with concerning symptoms, such as dyspnea and pain, their advance directives provided little guidance on how best to recognize and react to end-of-life, heroic interventions and oncologists themselves appear to have provided patients little guidance during their last outpatient visit about end-of-life decision-making.

Clearly, this study suggests a need to improve upon how cancer patients are counseled about the futility of end-of-life, heroic interventions, such as cardiopulmonary resuscitation, intensive care unit admission and intubation [7]. The current study emphasizes that it may not be the existence of the advance directive that matters but rather the content and specifics within such a document. Patients must be educated about futile outcomes to enable them to convey with accuracy their feelings about end-oflife, heroic measures. Furthermore, honest discussions between outpatient healthcare providers and patients on the verge of death might lead to fewer heroic and futile interventions and subsequently less cost. One limitation of our study is its retrospective study design; hence, future educational efforts, as alluded to above, might be better studied in a prospective fashion. 
Finally, although the current study focused on costs, aggressive treatment at the end of life may have a negative impact that reaches beyond financial endpoints. Previous studies show that aggressive care at the end of life begets worse quality of life for patients and worse coping with bereavement among family members [8]. Some investigators question whether overly aggressive end-of-life treatment among cancer patients may even represent a quality-of-care issue [9]. The retrospective nature of the current study precludes exploration of many of these factors, but future studies may choose to focus also on these aspects of end-of-life, heroic care as well.

In summary, the current study underscores the need for further research on how best to decrease the utilization of expensive, end-of-life, heroic measures among cancer patients who have incurable or difficult-to-treat malignancies. How best to educate cancer patients on the content of advance directives and how best to provide honest, informed end-of-life discussions with cancer patients and their family members merit further study. These approaches may prove advantageous in reducing end-of-life costs and perhaps also in improving quality of life and quality of care for cancer patients and their family members.

\section{Acknowledgment}

This work was funded in part by NIH grant 5K24CA131099.

\section{References}

1 http://progressreport.cancer.gov/doc_detail.asp?pid=1\&did=2009 (accessed November 27, 2010).

2 Weeks WB, Kofoed LL, Wallace AE, Welch G: Advance directives and the cost of terminal hospitalization. Arch Intern Med 1994; 154:2077-2083.

-3 Schneiderman LJ, Kronick R, Kaplan RM, Anderson JP, Langer RD: Effects of offering advance directives on medical treatments and costs. Ann Intern Med 1992;117:599606.
4 http://www.medterms.com/script/main/art. asp?articlekey $=2158$ (accessed January 12, 2011).

5 Bloomer M, Tan H, Lee S: End of life care. The importance of advance care planning. Aust Fam Physician 2010;39:734-737.

6 La Puma J, Orentlicher D, Moss RJ: Advance directives on admission. Clinical implications and analysis of the Patient Self-Determination Act of 1990. JAMA 1991;266:402405.

7 Fried TR, Drickamer M: Garnering support for advance care planning. JAMA 2010;303: 269-270.
-8 Wright AA, Zhang B, Ray A, Mack JW, Trice E, Balboni T, Mitchell SL, Jackson VA, Block SD, Maciejewski PK, Prigerson HG: Associations between end-of-life discussions, patient mental health, medical care near death, and caregiver bereavement adjustment. JAMA 2008;300:1665-1673

9 Earle CC, Landrum MB, Souza JM, Neville BA, Weeks JC, Ayanian JZ: Aggressiveness of cancer care near the end of life: is it a quality of care issue? J Clin Oncol 2008;26:38603866. 